Elsevier

NSM 01063

\title{
A multiwire microelectrode for single unit recording in deep brain structures
}

\author{
Dieter Jaeger, Sid Gilman and J. Wayne Aldridge \\ Department of Neurology. University of Michigan, Ann Arbor, MI (US A) \\ (Received 4 September 1989) \\ (Revised version received 4 January 1990 ) \\ (Accepted 17 January 1990)
}

Key words: Single unit recording; Data acquisıtion; Multichannel electrode; Awake anımal, Deep structure recording

\begin{abstract}
A method is described by which a single shaft multiwire microelectrode can be fabricated efficiently The resulting electrode can be attached to a commercial microdrive and used for single neuronal unit recording from one or more tracks in deep brain structures of anesthetızed or awake animals. The electrode consists of a 30 gauge stainless steel cannula through which multiple strands of 13 $\mu \mathrm{m}$ insulated tungsten microwires are threaded At the electrode tip the wires protude 3-4 $\mathrm{mm}$ from the cannula and are cut individually at suitable offsets. The tip is stabilized and fixed to the cannula with cyanoacrylate At the base of the electrode the wires are threaded through flexible plastic tubing that provides strain relief and are glued to individual pins of a miniature connector that plugs into a field effect transistor (FET) voltage follower. Good single unit recordings have been obtained routinely from the basal ganglia of awake, behaving monkeys with this electrode
\end{abstract}

\section{Introduction}

Multiple channel single unit recording is an attractive alternative to single channel recording because more data can be obtained for each recording site (Eichenbaum and Kuperstein, 1986). This is particularly advantageous when data are obtained from a trained behaving anımal since the number of trials an animal will perform is limited. A second advantage of multiple channel recording is that simultaneously recorded single units can be analyzed for functional interactions, for example, by constructing cross-correlograms (Perkel et al., 1967). This type of analysis allows a first step

Correspondence J Wayne Aldridge, MSc, Ph D, University of Michigan, Neuroscience Lab. Bldg, 1103 E. Huron, Ann Arbor, MI 48104, U S A Phone (313) 763-3706 towards describing the network level of neuronal functioning, which is essential to information processing by the brain.

In many single unit studies, recordings are obtained in dally penetrations so that over tıme a grid of tracks is formed to sample units from a structure. Most current multiple channel microelectrodes, however, can be implanted in one positıon only (Chorover and DeLuca. 1972, Eichenbaum et al., 1972; Palmer, 1978) or allow recording of a single track (Kubie, 1984; Diana et al.. 1987). Michalski et al. (1983) obtained multıple cortical penetrations with a bundle of $12 \mu \mathrm{m}$ tungsten microwires glued into a glass pipette. Some investigators have implanted arrays of microelectrodes (Kruger and Bach, 1981; Krüger, 1982) to sample multıple single units from a structure. This approach has been used for recording sites that are close to the brain surface. Current desıgns of printed circuit multıple channel elec- 
trodes are also suitable for superficial recordings only (Eichenbaum and Kuperstein, 1986). We have developed a method to fabricate multiple channel microelectrodes that are well suited for multiple penetrations to record from deep structures. We have used this electrode routinely for over a year to record from the basal ganglia of awake, behaving monkeys (Jaeger et al., 1988).

\section{Materials and method}

The overall structure of the electrode is shown and described in Figs. 1 and 2. A scanning electron micrograph of the electrode tip structure is shown in Fig. 3. With practice, an electrode can be manufactured in $90 \mathrm{~min}$. Each electrode can be used for multiple penetrations.

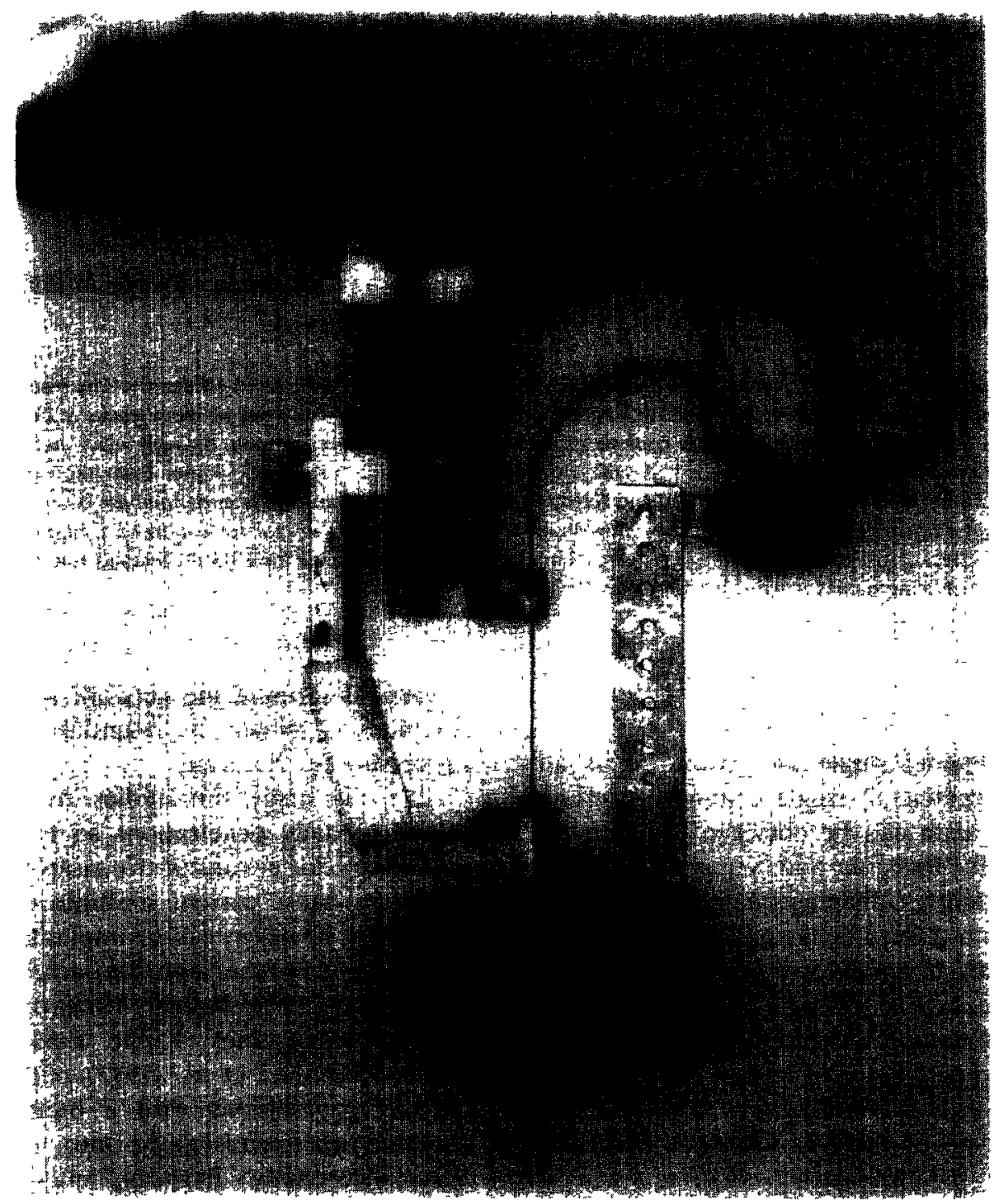

Fig. 1. Photograph of a multiwire mucroelectrode attached to a Kopf microdrive. The shaft of the electrode is clamped at the top. The lower portion of the shaft slides through a $\mathbf{2 3}$ gauge hypodermic needle that is used to penetrate dura and acts as a guiding cannula as well. It is fixed at a position such that it will not penetrate beyond superficial cortical layers. At the upper end of the electrode a microconnector plugs directly into an FET voltage follower. A flexible piece of plastic tubing between the base and the electrode shaft allows advancement of the electrode while the connector is firmly attached to the microdrive 


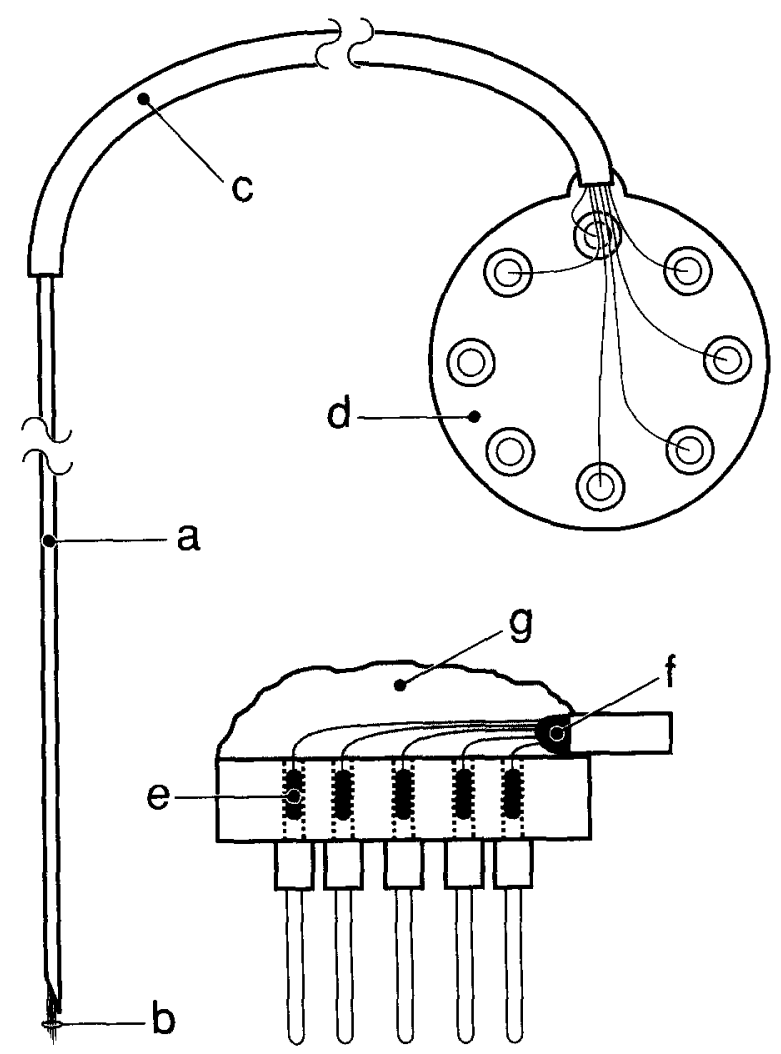

Fig. 2. Schematic drawing of the multıwire electrode The multiwire electrode consists of 4-10 strands of HM-L coated $13 \mu \mathrm{m}$ microwires (b) that are threaded through a 30 gauge stainless steel cannula (a) The tungsten wires protrude from the bevel of the cannula for $25-4 \mathrm{~mm}$ and each wire tip is arranged at an offset of 50-200 $\mu \mathrm{m}$ from the other tips On the base of the electrode each wire is connected to a single pin hole of an Augat transistor microsocket (d), which serves as a connector to a FET voltage follower Between the base of the electrode shaft and the connector all wires are guided through a length of flexible plastic tubing (c) The inset shows another view of the connector The shaded area indicates the protective epoxy cover (g) The wires are connected using silver-based epoxy (e) The entrance of the wires to the flexuble tubing is blocked with vaseline (f) to prevent epoxy from entering the tubing.

To begin electrode construction, a shaft is prepared by cutting 30 gauge stainless steel tubıng (Small Parts, Inc.) to the desired length and bevelling it on one side with an abrasıve disk mounted on a dremel tool. The cannula ends are then cleaned of burrs with a $\# 00$ insect pin mounted on a pin chuck. A steel wire is threaded through the cannula to check for obstructions and to smooth the insides of the cannula ends. Air is blown through the cannula to clear it of any metal particles that have collected inside. A bundle of microwires can then be threaded through the prepared cannula. Four to 10 strands of $13 \mu \mathrm{m}(0.0005$ in) HM-L coated microwire (Californıa Fine Wire Company) of the desired tip to connector length with $10 \mathrm{~cm}$ added are cut. To simplify threading, all wire strands are glued together at one end with penetratıng superglue (Super Bonder 420, Loctite Corporation). The glued bundle is then threaded through the 30 gauge cannula from base to bevel by hand. This is best done at $40 \times$ magnification with the aid of a binocular microscope. During threading the cannula is held by an alligator clip mounted to a suitable stand. The tungsten wires should not be held with metal forceps as this can cause the HM-L coating to break. After the tungsten wires are threaded through the cannula, the glued part is cut off. The separated wire tips are then extended to approximately $10 \mathrm{~mm}$ beyond the cannula bevel and cut individually at desired offsets with fine, sharp scissors. The whole bundle of tips is then pulled back so that tips protrude between 2.5 and $4.0 \mathrm{~mm}$ from the cannula bevel. At the tip base, a drop of penetrating superglue is then applied with a wooden applicator to fix the wire positions and stabilize the tip. If the wire ends are splayed apart or curve excessively, the tip can be redone by unbondıng it with acetone, realigning the wire ends and gluing them back together. Unbondıng and realıgning the tıps is best done with a pair of cotton tipped applicators at $25 \times$ magnification. To complete the electrode the bundle of microwires emerging at the base of the cannula is threaded through a piece of protective plastic tubing and the wire ends are glued to individual pinholes of an 8-pin Augat transistor socket. To do this the plastic tubing is first glued to the transistor socket with superglue. The tubing should have an inner diameter just large enough to slide over the end of the 30 gauge shaft of the electrode. The wire bundle is threaded through the plastic tubing with the attached Augat socket. The wire ends are again glued together before threading. A drop of mineral oll is then applied to the junction of 30 gauge cannula, tungsten wires and plastic tubing before the end 


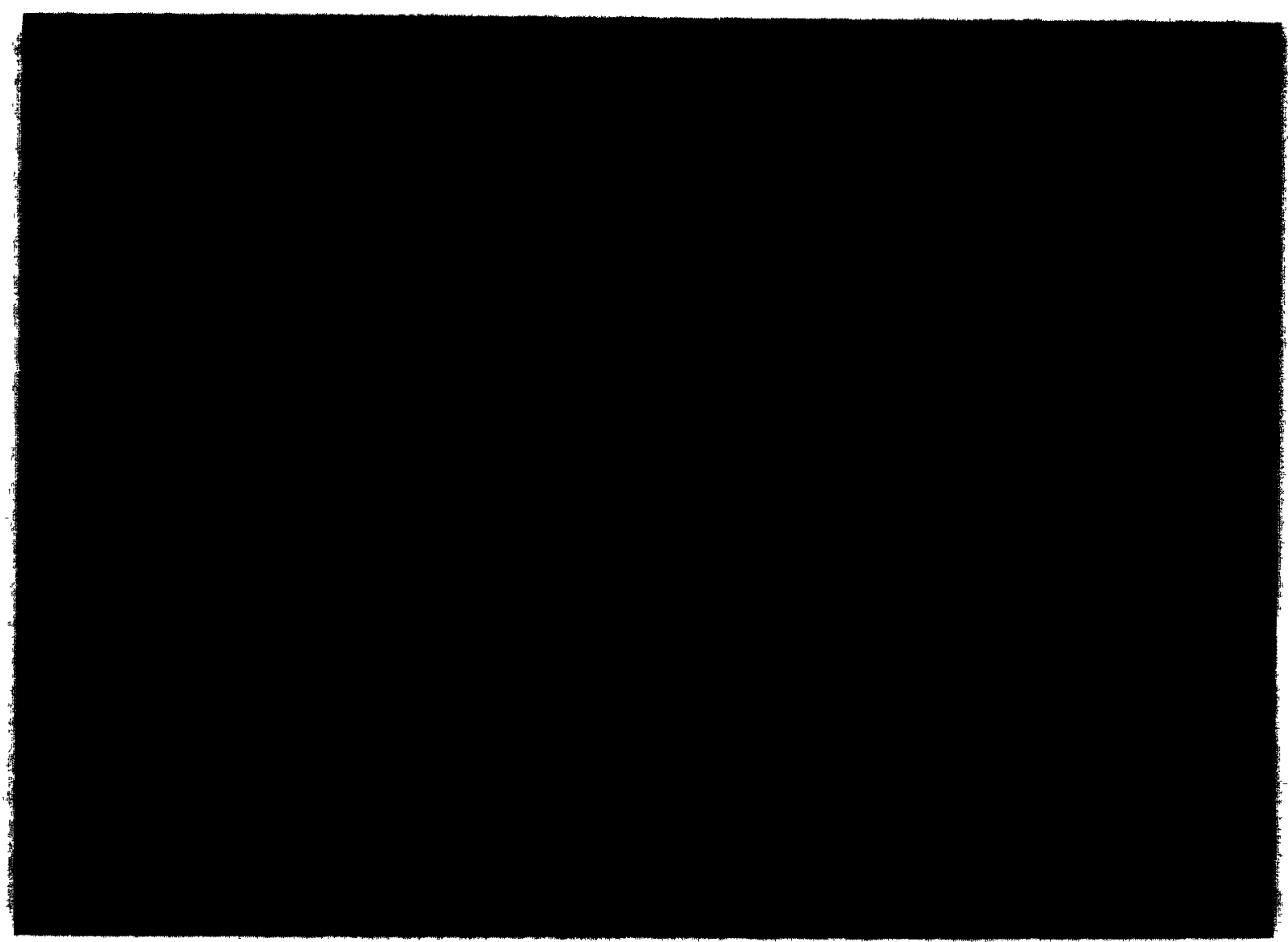

Fig. 3 Scanning electron micrograph of the electrode tıp The tungsten microwire ends are glued together with penetrating superglue to avoid bending and divergence of individual wires while the electrode is advanced into the brain Note that the superglue does not cover the recording tips of the tungsten wire

of the tubing is slid over the base of the 30 gauge cannula. The oll is sucked into the plastic tubing by capillary action. Applying oil to the wire bundle in this way greatly reduces recording artifacts due to the friction of tungsten microwires sliding against each other inside the cannula and plastic tubing. This is particularly important when recordings are taken from moving animals. The HM- $L$ insulation is stripped off the ends of the tungsten wires with two pairs of watchmaker forceps at $12-16 \times$ magnification. The exposed tungsten wire ends are each glued into one pin hole of the connector with conductive silver epoxy. As the last step, 5 min epoxy is used to cover the entire back side of the connector to protect the tungsten wire ends during electrode handling. To avoid breakage of the wire bundle inside the flexible tubing, care must be taken that no epoxy enters the end of the plastic tubing, which is best blocked with vaseline or grease.

The electrode is now ready to be attached to a microdrive. We have used a Kopf hydraulic microdrive (model 1207B) for this purpose. The impedances of individual wires should be tested, and in our experience acceptable impedances, tested at $1000 \mathrm{~Hz}$, range from $600 \mathrm{~K} \Omega$ to $1.5 \mathrm{M} \Omega$. In addition, a DC current from a $9 \mathrm{~V}$ source with a 1 $\mathrm{M} \Omega$ in series resistor can be passed through the wires with the wire tip as the negative pole to produce at the wire tips bubbles that can be 
observed through the binocular microscope. This test is instrumental in matching each electrode wire tip to each pin on the Augat socket.

\section{Results and discussion}

We have used microelectrodes with six $13-\mu \mathrm{m}$ tungsten wires for recording unit activity from the basal ganglia of behaving monkeys for over a year. Recording artifacts due to animal movement were successfully elımınated by applyıng mineral oil to the microwires inside the electrode shaft and plastic tubing. With this method, artifact free recordings could be obtained even though the anımals were allowed free head movements. At each recording site we choose 4 of the 6 electrode wires for data collection. The quality of unit isolation (Fig. 4) and the ability to hold single units was similar to conventional tungsten microelectrodes (Micro Probe, Inc., WE500315A), which we have used in earlier studies with awake monkeys.

In addition to $13 \mu \mathrm{m}$ HM-L coated tungsten wires, we have tested multiwire electrodes with 25 $\mu \mathrm{m}$ HM-L coated tungsten wires and $25 \mu \mathrm{m}$ HM-L coated stainless steel wires. Single unit isolation was less satisfactory than for $13 \mu \mathrm{m}$ tungsten wires in both cases. Diana et al. (1987) report better unit separation with multiwire electrodes

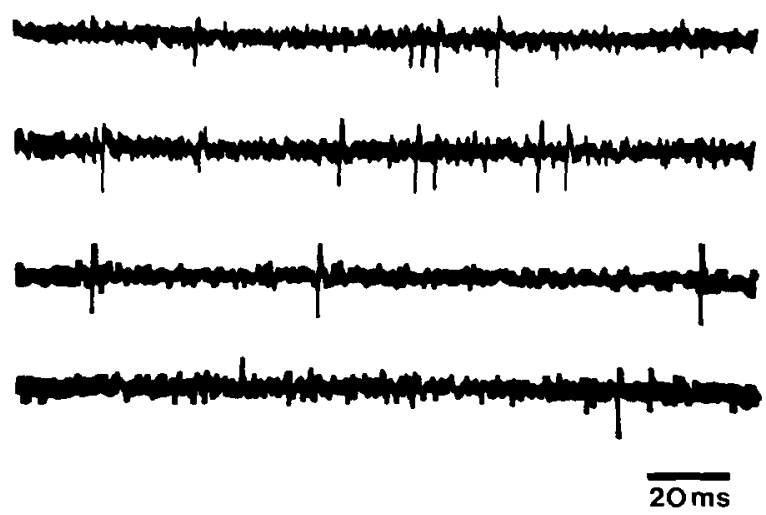

Fig. 4 Four simultaneous recording traces from the putamen of a behaving monkey These traces were recorded from a multiwire microelectrode with $13 \mu \mathrm{m}$ tungsten wires A unit can be discriminated on each channel. The first trace shows two differently sized spikes that can be discriminated as 2 single units when they use $18 \mu \mathrm{m}$ steel wires as compared with $25 \mu \mathrm{m}$ steel wires, which is in agreement with our result that smaller diameter wires are better suited for single unit recording. Diana et al (1987) also note that for steel wires better unit isolation is obtained when the wire is double coated with Parylene and HM-L.

Kaltenbach and Gerstem (1986) report a method of sharpenıng the tips of flush cut $25 \mu \mathrm{m}$ HM-L coated tungsten wires. Sharpened electrodes result in better single unit isolation in their experience. Sharpened $25 \mu \mathrm{m}$ tungsten wire electrodes were reported to have impedances from 300 $\mathrm{K} \Omega$ to $1.5 \mathrm{M} \Omega$, which is similar to our impedances for unsharpened $13 \mu \mathrm{m}$ tungsten wires Improvement in unit separation from sharpening $13 \mu \mathrm{m}$ wires would probably be less than for $25 \mu \mathrm{m}$ wires because flush cut $13 \mu \mathrm{m}$ wires have finer tips than $25 \mu \mathrm{m}$ wires even before sharpenıng

Eichenbaum and Kuperstein (1986) in their review on multıchannel microelectrodes stress the advantage of printed circuit microelectrodes over bundled microwire designs. The former can be mass produced reliably while the latter need to be manufactured individually We agree with this judgment in principle, however, to our knowledge there are no microcircuit electrodes avalable that allow recording from deep structures It is difficult to achieve this goal since long electrode shafts cannot be bult from a silicon wafer and to our knowledge connectıng wafer electrode tıps to wires has not been achieved on a scale small enough to fit inside a steel cannula sutable for depth recordings. Thus, currently printed microcircuit electrodes seem to be best suited for cortical recordings

\section{References}

Chorover, S L and DeLuca, A -M (1972) A sweet new mult1ple electrode for chronic single unit recording in moving animals Physiol Behav, 9.671-674

Diand, M, Garcia-Munoz, M and Freed, C R (1987) Wire electrodes for chronic single unit recording of dopamine cells in substantia nigra pars compacta of awake rats $J$ Neuroser Methods 21 71-79

Eıchenbaum, H. Pettıohn, D, DeLuca. A-M and Chorover. 
S L (1977) Compact minature microelectrode-telemetry system. Physiol. Behav, 18 1175-1178

Eichenbaum, H. and Kuperstein, M. (1986) Extracellular neural recording with multichannel microelectrodes J. Electrophysiol. Tech., 13 189-209

Jaeger, D., Gilman, S. and Aldndge, J.W (1988) Single unt activity of primate caudate nucleus in a precue task Soc. Neuroscl Abstr, 14, part 1719

Kaltenbach, J A and Gerstein, G L (1986) A rapıd method for production of sharp tips on preınsulated microwires. $J$ Neuroscl. Methods, 16: 283-288

Kruger, J. and Bach, M. (1981) Simultaneous recol ding with 30 microelectrodes in monkey visual cortex Exp. Brain Res. 41 191-194

Krüger, J. (1982) A 12-fold microelectrode for recording from vertically aligned cortical neurones J Neuroser Methods, 6: $347-350$.

Kubie, J L. (1984) A driveable bundle of microwires for collectıng single-unit data from freely-moving rats Physiol Behav, 32 115-118.

Mıchalskı, A., Gersteın, G.L , Czarkowska, J and Tarneckı, R (1983) Interactions between cat striate cortex neurons. Exp Brain Res, 51: 97-107.

Palmer, C. (1978) A microwire technique for recording single neurons in unrestrained anımals Brain. Res Bull , 3. 285289

Perkel, D H., Gerstein, G.L. and Moore, G.P. (1967). Neuronal spike trains and stochastic processes II Simultaneous spike trains Bıophys. J, 7 419-439 